\title{
Mixed transition metal oxides for efficient electrochemical splitting of water to hydrogen and oxygen
}

\author{
M. Frites, A. Simpson, R. Gautam \& S. U. M. Khan \\ Department of Chemistry and Biochemistry, Duquesne University, USA
}

\begin{abstract}
In this study non-noble and non-rare metal based mixed transition metal oxides were synthesized by spray pyrolysis and used as electrocatalysts for the efficient splitting of water to hydrogen and oxygen in alkaline medium. The mixed oxides of nickel and cobalt (Ni-Co-oxide) of specific compositions (3:1 ratio) generated

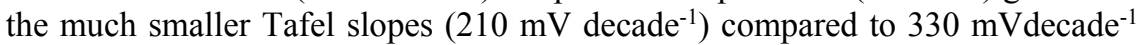
and $440 \mathrm{mV}$ decade $^{-1}$ for Co-Oxide and Ni-oxide respectively indicating its enhanced electro-catalytic activity for oxygen evolution reaction (OER) during water splitting. Also, the mixed oxides of $\mathrm{Ni}$ and $\mathrm{Fe}$ (Ni-Fe-oxide) of specific compositions (4:1 ratio) generated the smaller Tafel slopes $\left(360 \mathrm{mV}\right.$ decade $\left.^{-1}\right)$ compared to $440 \mathrm{mVdecade}^{-1}$ and $500 \mathrm{mV}$ decade $^{-1}$ for Ni-oxide and Fe-oxide respectively for OER during water splitting. At the measured potential of 1.0 V/SCE the current density of $130.0 \mathrm{~mA} \mathrm{~cm}^{-2}$ was observed for water splitting at $\mathrm{Ni}-\mathrm{Co}$ mixed oxide compared to $60.0 \mathrm{~mA} \mathrm{~cm}^{-2}, 31.0 \mathrm{~mA} \mathrm{~cm}{ }^{-2}, 30.0 \mathrm{~mA} \mathrm{~cm}^{-2}$ and $28.0 \mathrm{~mA} \mathrm{~cm}^{-2}$ at mixed Ni-Fe oxide (4:1 ratio), Co-oxide, Ni-Oxide and Fe-oxide respectively. These results show more than four-fold increase in rate of water splitting at the mixed $\mathrm{Ni}-\mathrm{Co}$ oxide and more than two-fold at mixed $\mathrm{Ni}-\mathrm{Fe}$ oxide due to synergetic effects compared to their individual oxides. An order of magnitude of higher values of current density for water splitting on these electrodes compared to recently reported results can be attributed also to high internal surface area due to porosity of the oxide films synthesized by spray pyrolysis method as it is observed in SEM results.
\end{abstract}

Keywords: mixed transition metal oxides, electrocatalytic anodes, water splitting, water oxidation, porous films, oxygen evolution. 


\section{Introduction}

Water splitting reaction to produce hydrogen and oxygen is a well-known electrochemical process. It requires an external applied potential to overcome the thermodynamic, ohmic and kinetic barriers to drive water-splitting reaction. Pollution free hydrogen fuel generation and the flexibility of choosing the external power sources such as electrical grid or solar cell [1] have made water electrolysis the most desirable compared to traditional processes that use fossil fuels as hydrogen source. The abundant and cost effective solar energy can be used to generate the external power required to drive the electrolysis reaction. However, the present water electrolyzer's low current efficiency has made the process less competitive compared to steam reforming methanol or natural gas [2]. Most of the research efforts to improve the water electrolysis efficiency have been focusing on the energetically challenging water oxidation to generate oxygen at anodes and thereby facilitate hydrogen evolution reaction (HER) at cathodes during water splitting reactions $\left(\mathrm{H}_{2} \mathrm{O} \rightarrow \mathrm{H}_{2}+1 / 2 \mathrm{O}_{2}\right)$. Earlier work included noble metals and rare metal oxides such as $\mathrm{RuO}_{2}$ or $\mathrm{IrO}_{2}$ for oxygen evolution reaction (OER). However, the dependence on rare metals is not a solid approach because a massive worldwide manufacturing of noble/rare metal-based electrolyzers will drive up their price further. Perhaps the most suitable approach is to use earth abundant transition metals and their oxides or a combination of transition metals and their oxides to quell the overpotential required for oxygen evolution at the anode surface. Ni, Co and their oxides have been extensively studied individually or as alloys as electrocatalytic electrodes for the oxygen evolution reaction [3-12]. Previous investigations on transition metals $\mathrm{M}$-single oxides $(\mathrm{M}=\mathrm{Ni}, \mathrm{Co}$ or $\mathrm{Fe})$ were focused on enhancing the catalytic activity for OER by modifying the surface morphologies and studying their behavior during OER. However, the extent to which the catalytic activity of these transition metal single oxides toward OER can be enhanced was found to be rather limited. The other available alternative to use earth abundant transition metal based electrodes for OER is the mixed first row transition metal oxides. The synergetic effects of the later on electrocatalytic activities were recognized earlier [13-20]. The effect of methods of synthesis of these mixed oxides electrodes and their composition on electro-catalytic activity for OER were also noted [12].

In this study mixed Ni-Co-oxides, mixed Ni-Fe oxides with different atomic ratios, individual $\mathrm{Ni}$-oxide, $\mathrm{Co}$-oxide and $\mathrm{Fe}$-oxides were synthesized by spray pyrolysis method on conducting fluorine doped tin oxide (FTO) coated glass substrate. The electrocatalytic activity of the mixed $\mathrm{Ni}$-Co-oxide and $\mathrm{Ni}$-Fe oxide anodes for oxygen evolution in basic medium was assessed in terms of current density and compared to those of individual oxides. The surface morphology and composition of these oxide electrodes were characterized using the scanning electron microscopy (SEM) and energy dispersive spectroscopy (EDS) respectively. 


\section{Experimental}

Commercially available fluorine doped tin oxide (FTO) coated conducting glass substrates were cleaned in a sonicator using acetone, Acetone: Di-water (50:50) and Di-water respectively. Each step lasted 30 minutes. The cleaned FTO glass substrates were then dried under dry Argon gas. The resistivity of the resulting ITOs was found to be within $14-20 \mathrm{ohm} \mathrm{cm}$ at room temperature. Aqueous solutions of $0.05 \mathrm{M}$ Ni-Chloride, $0.05 \mathrm{M}$ Co-nitrate and $0.05 \mathrm{M} \mathrm{Fe-Nitrate} \mathrm{were}$ used as spray solutions to synthesize Ni-oxide, Co-oxide and Fe-oxide respectively. Different volume ratios of these aqueous solutions were also used to synthesize mixed $\mathrm{Ni}-\mathrm{Co}$ oxides and mixed $\mathrm{Ni}-\mathrm{Fe}$ oxides. The spray operation was carried out for a total of $30 \mathrm{sec}$ having three $10 \mathrm{sec}$ spray periods on an FTO conducting glass substrate at a temperature of $180^{\circ} \mathrm{C}$ using a pneumatic nozzle and oxygen as the carrier gas with a pressure of $137.8 \mathrm{kPa}$. In between each spray period there were intervals of $\sim 10 \mathrm{~min}$ for the substrate temperature to be raised back to $180^{\circ} \mathrm{C}$ on a hot plate. A conducting silver epoxy was applied to the four edges of the FTO glass to ensure a uniform electrical conductivity across the electrode surface area during water electrolysis. After the spray the silver epoxy at the edges of the electrodes was covered with a non-conductive resin based epoxy. Linear sweep voltammetry was used as the main tool to assess the electrocatalytic performance of these electrodes toward OER. A three-electrode configuration in a single-compartment cell was used, with Ni-Co mixed oxides, $\mathrm{Ni}-\mathrm{Fe}$ mixed oxide, Ni-oxide, Co-oxide or Fe-oxide as a working electrode, platinum wire as a counter electrode, and SCE as a reference electrode. The single compartment cell was filled with $2.5 \mathrm{M} \mathrm{KOH}$ as an electrolyte solution. The linear sweep CV curves of the catalysts were obtained using a scanning potentiostat (Versa STAT 3 running Versa Studio software, Princeton Applied Research). A scan rate of $50 \mathrm{mV} \mathrm{s}^{-1}$ was used to minimize the extra resistances developed at the electrode-solution interfaces by the bubbles of oxygen and hydrogen generated during water splitting reactions.

Scanning electron microscopy (SEM) was used to characterize the surface morphology of these synthesized thin films and was performed on a highresolution Hitachi S-3400 SEM using a $2.0 \mathrm{kV}$ focus voltage. The Hitachi S-3400 SEM equipped with a Bruker Quantax energy dispersive spectrometer was also used for EDS analysis. Samples were mounted on a double-sided carbon tape affixed to an Aluminum specimen holder. The EDS spectra were collected at a working distance of $10 \mathrm{~mm}$ and an accelerating voltage of $15 \mathrm{KV}$.

\section{Results and discussion}

Figure 1(a) shows the current density versus the external applied potential curves for mixed Ni-Co oxide, Ni-oxide, Co-oxide, Fe-oxide and bare FTO during OER. In this Figure the mixed Ni-Co oxide (synthesized using 3:1 volume ratio of 0.05 $\mathrm{M} \mathrm{NiCl}_{2}$ and $0.05 \mathrm{M} \mathrm{Co}\left(\mathrm{NO}_{3}\right)_{2}$ in spray solution and sprayed for total of $\left.30 \mathrm{sec}\right)$ catalyst showed the highest and bare FTO showed the lowest electrocatalytic 


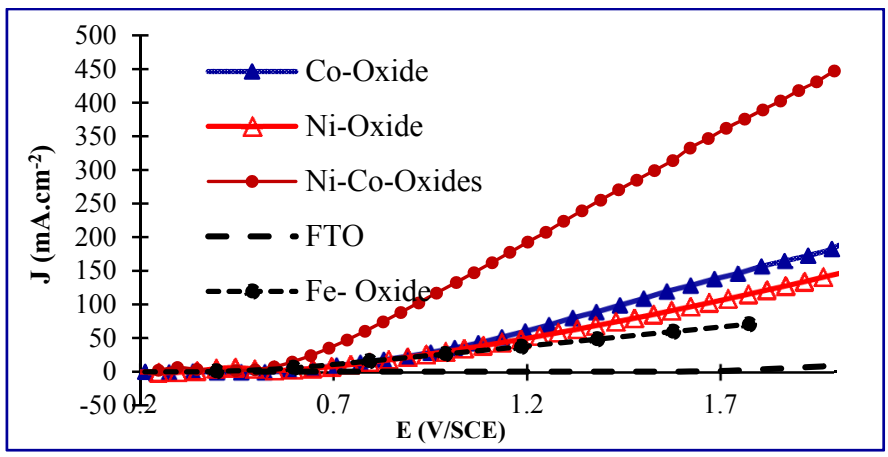

(a)

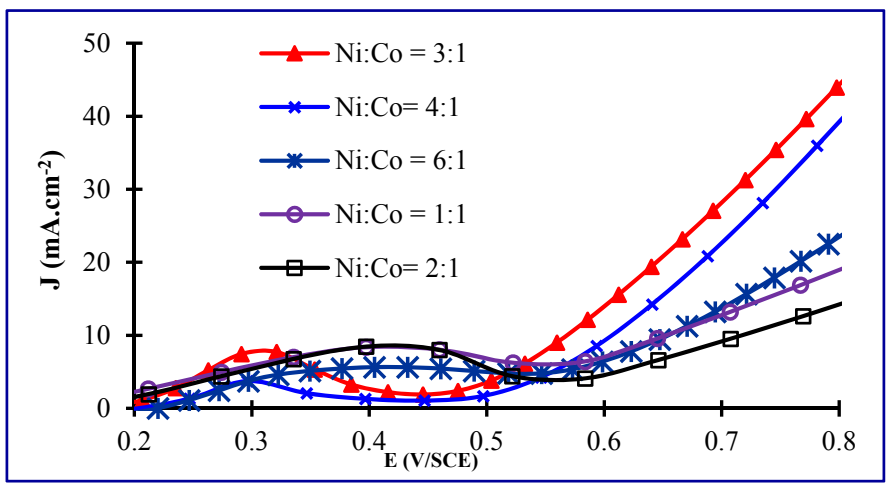

(b)

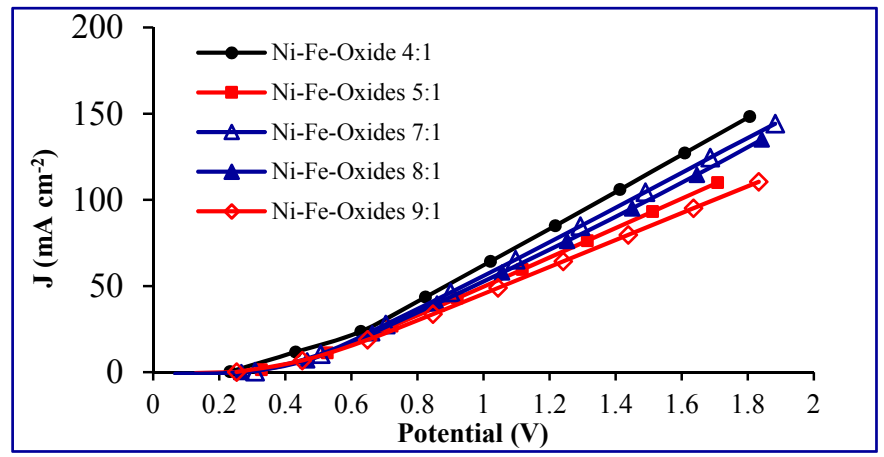

(c)

Figure 1: Current density, $\mathrm{J}\left(\mathrm{mA} \mathrm{cm}^{-2}\right)$ versus applied potential (E, V/SCE) during OER (a) at bare FTO conducting glass, Ni-oxide, Co-oxide, Fe-oxide and mixed Ni-Co-oxide electrodes (b) at mixed $\mathrm{Ni}$-Co-oxides of various compositions deposited on FTO coated glass substrate (c) at mixed Ni-Fe oxides of various compositions in $2.5 \mathrm{M}$ $\mathrm{KOH}$ solution at a scan rate of $50 \mathrm{mV} \mathrm{s}^{-1}$. 
activity toward OER during water splitting. The observed sharp rise in current density for OER at Ni-Co-mixed oxides at $0.7 \mathrm{~V} / \mathrm{SCE}$ compared to those at the individual $\mathrm{Ni}$ and $\mathrm{Co}$ oxides indicates that the presence of $\mathrm{Co}$ along with $\mathrm{Ni}$ generates active mixed oxide surfaces having lower overpotential for OER. For example, at $1.0 \mathrm{~V} / \mathrm{SCE}$ the observed current density of $130.0 \mathrm{~mA} \mathrm{~cm}{ }^{-2}$ at mixed $\mathrm{Ni}$-Co-oxide is over 4-fold higher compared to observed current density of $\sim 30.0$ $\mathrm{mA} \mathrm{cm}{ }^{-2}$ on their individual oxides. Similarly, at $1.0 \mathrm{~V} / \mathrm{SCE}$ the observed current density of $60.00 \mathrm{~mA} \mathrm{~cm}^{-2}$ at mixed $\mathrm{Ni}-\mathrm{Fe}$ oxide (synthesized using 4:1 volume ratio of $0.05 \mathrm{M} \mathrm{NiCl}_{2}$ and $0.05 \mathrm{M} \mathrm{Fe}\left(\mathrm{NO}_{3}\right)_{3}$ in spray solution and sprayed for total of $30 \mathrm{sec}$ ) is over 2-fold higher compared to observe current density of $28.00 \mathrm{~mA}$ $\mathrm{cm}^{-2}$ on Fe-oxide itself (see Figures 1(a) and 1(c)).

The observed broad peaks prior to oxygen evolution in Figure 1(b) clearly indicates the existence of direct relationship between the position of these peaks and an early oxygen evolution. In the case of mixed Ni-Co-oxide electrodes of 3:1 ratio shows the formation of electro-chromic $\mathrm{Ni}$-oxide at lower potential compared to other compositions [21]. Consequently, mixed Ni-Co oxide of 3:1 ratios shows the highest synergetic electrocatalytic effect towards OER. However, in Figure 1(c) no clear broad peaks are observed for mixed Ni-Fe oxides of various composition. In this case the mixed oxide having $\mathrm{Ni}$ :Fe ratio of $4: 1$ shows highest electrocatalytic effect towards OER during water splitting. However, the synergetic effect between nickel and iron towards electrocatalysis of OER is lower than that of nickel and cobalt. But cost wise iron will be lower in cost than cobalt to offset its lower synergetic electrocatalytic effect compared to cobalt.

Figure 2 shows the Tafel plots of these five metal oxides. The mixed Ni-Co oxide anode sprayed pyrolytically on FTO exhibits the lowest Tafel slope of 210 $\mathrm{mV} /$ decade compared to $330 \mathrm{mV} /$ decade for Co-oxide and $440 \mathrm{mV}$ decade $^{-1}$ for $\mathrm{Ni}$-oxide anodes for OER, $360 \mathrm{mV}$ decade $^{-1}$ for mixed Ni-Fe oxide and $500 \mathrm{mV}$ decade $^{-1}$ for Fe-oxide anodes for OER during water splitting. The lowest Tafel slope for mixed Ni-Co oxide and mixed Ni-Fe oxide compared to their individual oxides indicated their higher electrocatalytic activity due to synergetic effect $[13,14]$ of mixed oxides that generated active surface sites for efficient OE.

The surface morphologies and the corresponding compositions were obtained from the scanning electron microgram (SEM) pictures and the corresponding energy dispersive spectroscopic (EDS) data given in Figure 3 for Co-oxide, Nioxide and mixed Ni-Co-oxides respectively. The microgram in Figure 3 clearly indicates the rough and porous surface of Co-oxide and the corresponding EDS data shows the presence of $\mathrm{Co}, \mathrm{O}$ and $\mathrm{Sn}$ on the surface as expected. Similarly, the microgram in Figure 3 shows a less rough surface of $\mathrm{Ni}$ oxide and the corresponding EDS data showed the presence of Ni, O and $\mathrm{Sn}$. The microgram of mixed Ni-Co oxide (Figure 3) shows the roughest and most porous surface. The corresponding EDS data shows the presence of $\mathrm{Ni}, \mathrm{Co}, \mathrm{Sn}$ and $\mathrm{O}$ as expected. These rough and porous surfaces are responsible for the enhanced internal surface area that helped to generate an order of magnitude higher current densities compared to recently reported results [15-19]. The internal surface area for the rough and porous surface could be $\sim 10^{4}$ times higher than the geometrical surface area [16]. 


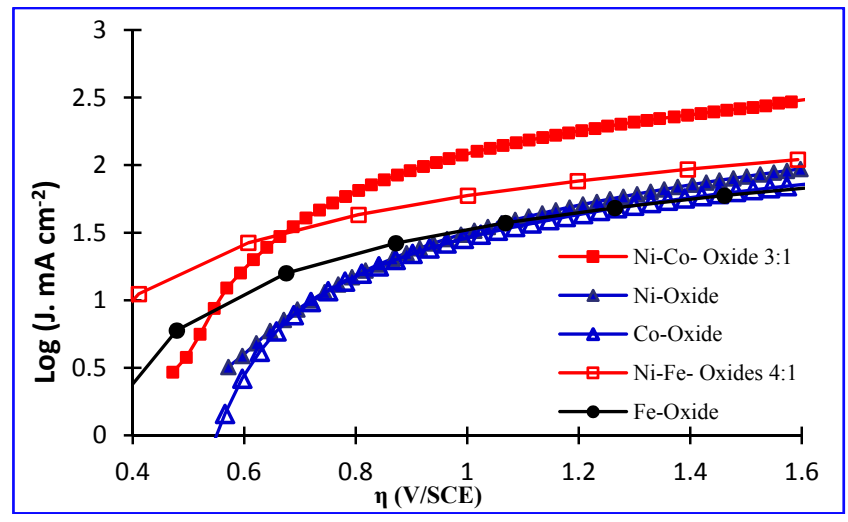

Figure 2: Tafel plots obtained from the Log (current density, J) vs overpotential, $\eta)$ for OER at mixed $\mathrm{Ni}-\mathrm{Co}$ oxide, mixed $\mathrm{Ni}-\mathrm{Fe}$ oxide, Ni-oxide, $\mathrm{Co}$-oxide and $\mathrm{Fe}$-oxide electrodes. The overpotentials for OER were obtained using $\eta=E_{\text {meas }}-\mathrm{E}_{\text {OER }}^{0}$ where $\mathrm{E}^{0}$ OER $=0.116 \mathrm{~V} / \mathrm{SCE}$ is the standard oxygen evolution potential in $2.5 \mathrm{KOH}$ electrolyte and $\mathrm{E}_{\text {meas }}$ is the measured potential during OER.
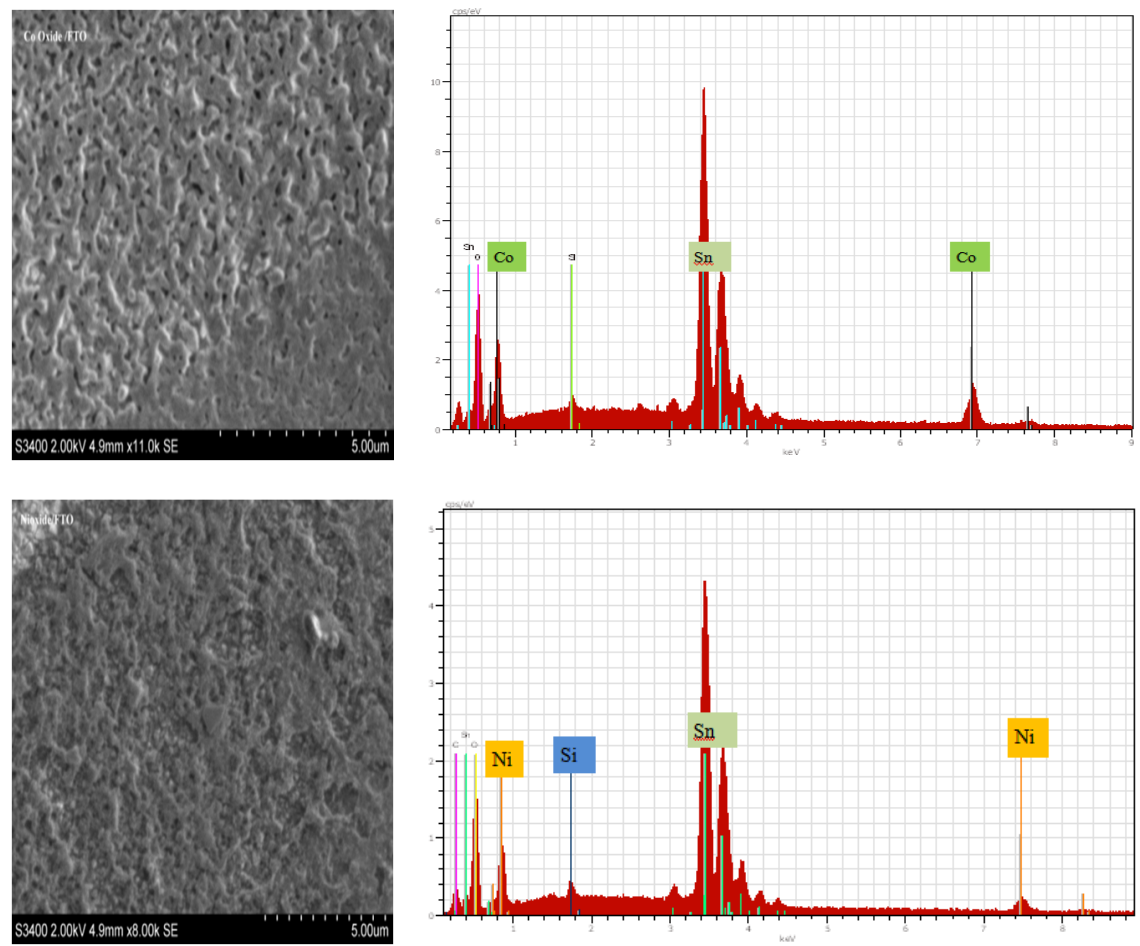

Figure 3: $\quad$ SEM pictures and EDS results of Co-oxide, Ni-oxide and mixed NiCo mixed oxide on FTO coated glass substrate. 

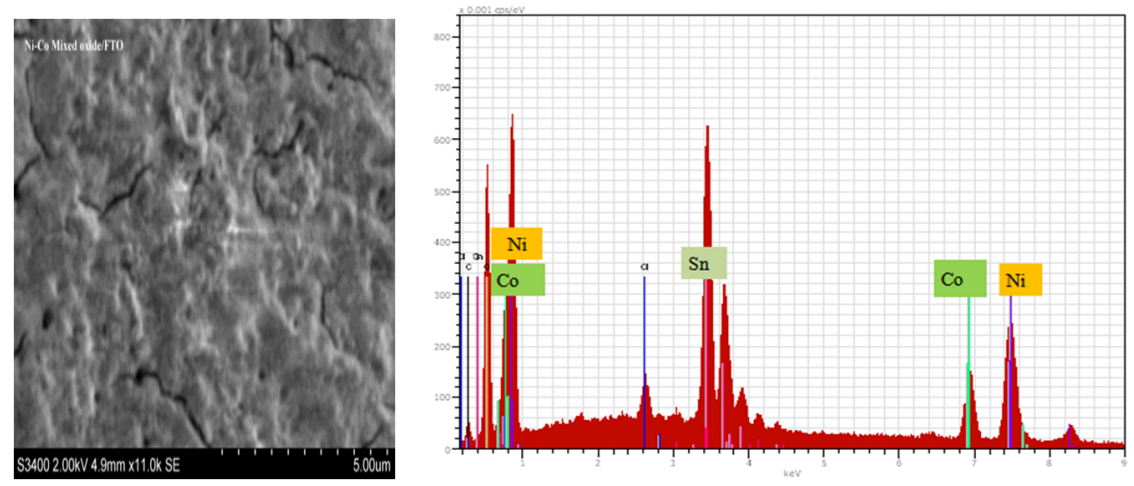

Figure 3: Continued.

\section{Conclusions}

Electrocatalytically active porous with high internal surface area Ni-oxide, Co-oxide, Fe-oxide, mixed Ni-Co-oxide and mixed Ni-Fe oxide anodes can be synthesized by spray pyrolysis method on fluorine doped tin oxide (FTO) coated glass substrate. The synergetic effect of mixed oxides helped to generate more active electrocatalytic porous high internal surface area anodes for highly efficient oxygen evolution reaction (OER) during water splitting reactions. Thus, these earth abundant mixed transition metal oxide anodes can be coupled with active metal or mixed metal cathodes to develop solar cell powered electrolyzers for efficient generation of oxygen and hydrogen fuel by water splitting.

\section{References}

[1] M. Frites, W.B. Ingler Jr., S. U. M. Khan, Efficient Anode and Cathode Materials for Amorphous Silicon Solar Cell Driven all Solar Electrolysis of Water, Green, 1(1), pp. 97-103, 2011.

[2] D. Marcelo and A. Dell'Era, Economical electrolyser solution, Int. J. Hydrogen Energy, 33(12), pp. 3041-3044, 2008.

[3] J. B. Gerken, J. G. McAlpin, J. Y. C. Chen, M. L. Rigsby, W. H. Casey, R. D. Britt, and S. S. Stahl, Electrochemical water oxidation with cobalt-based electrocatalysts from $\mathrm{pH}$ 0-14: the thermodynamic basis for catalyst structure, stability, and activity, J. Am. Chem. Soc., 133(36), pp. 1443114442, 2011.

[4] M. W. Kanan and Daniel G. Nocera, In Situ Formation of an OxygenEvolving Catalyst in Neutral Water Containing Phosphate and $\mathrm{Co}^{2+}$, Science, 321, pp. 1072-1075, 2008.

[5] M. Risch, V. Khare, I. Zaharieva, L. Gerencser, P. Chernev, and H. Dau, Cobalt-oxo core of a water-oxidizing catalyst film, J. Am. Chem. Soc., 131(20), pp. 6936-6937, 2009.

[6] Q. Zhang, Z.D. Wei, C. Liu, X. Liu, X.Q. Qi, S.G. Chen, W. Ding, Y. Ma, F. Shi, Y.M. Zhou, Int. J. Hydrogen Energy, 37(1), pp. 10479-10485, 2012.

[7] E. B. Castro, S.G. Real, L.F. Pinheiro Dick, Impedance Study of Spinel 
Type Fe-Co3O4 Oxide Thin Film Electrodes in Alkaline Medium Intl. J. of Hydro. Ener., 29, pp. 225-230, 2004.

[8] C. C. Hu, Y. S. Lee, T. C. Wen, The physicochemical/electrochemical properties of binary Ni-Co oxides, Mater. Chem. Phys., 48, pp. 246-250, 1997.

[9] G.C. Silva a, C.S. Fugivara a, G. Tremiliosi Filho b, P.T.A. Sumodjo c, A.V. Benedetti, Electrochemical behavior of cobalt oxide coatings on cold-rolled steel in alkaline sodium sulfate, Electrochim. Acta, 47(12), pp. 1875-1883, 2002.

[10] E. B. Castro, C. A. Gervasiz, J. R. Vilche, E. B. Castro, C. A. Gervasiz, J. R. Vilche, Oxygen evolution on electrodeposited cobalt oxides, J. Appl. Electrchem., 28(8), pp. 835-841, 1998.

[11] H. S. Shim, V. R. Shinde, H. J. Kim, Y. E. Sung, W. B. Kim, Porous cobalt oxide thin films from low temperature solution phase synthesis for electrochromic electrode, Thin Solid Films, 516(23), pp. 8573-8578, 2008.

[12] C. Bocca, A. Barbucci, M. Delucchi, G. Cerisola, Oxygen evolution reaction (OER) in an alkaline solution, Int. J. Hydrogen. Energy, 24(1), pp. 21-26, 1999.

[13] C.F. Boots and S. Trasatti, Effect of Composition on the Electrocatalytic Activity of the Ternary Oxide $\mathrm{Ru}_{0.3} \mathrm{Ti}_{(0.7-x)} \mathrm{Sn}_{x} \mathrm{O}_{2}$ I. Oxygen Evolution from $\mathrm{HClO}_{4}$ Solutions, J. Electrohem. Soc., 137(12), pp. 3784-3789, 1990.

[14] S. Trasatti, Physical electrochemistry of ceramic oxides, Electrochim. Acta, 36, 225-241, 1991.

[15] R. D. L. Smith, M. S. Prévot, R. D. Fagan, Z. Zhang, P. A. Sedach, M. K. J. Siu, S. Trudel, C. P. Berlinguette, Photochemical Route for Accessing Amorphous Metal Oxide Materials for Water Oxidation Catalysis, Science, 340, pp. 60-63, 2013.

[16] J. Suntivich, K. J. May, H. A. Gasteiger, J. B. Goodenough and Y. ShaoHorn, A perovskite oxide optimized for oxygen evolution catalysis from molecular orbital principles, Science, 334, pp. 1383-1385, 2011.

[17] L. Trotochaud, J. K. Ranney, K. N. Williams and S. W. Boettcher, Solutioncast metal oxide thin film electrocatalysts for oxygen evolution, J. Am. Chem. Soc., 134(41), pp. 17253-17261, 2012.

[18] L. Trotochaud and S. W. Boettcher, Precise oxygen evolution catalysts: Status and opportunities, Scripta Materialia, 74, pp. 25-32 (2014).

[19] R. D. L. Smith, M. S. Prévot, R. D. Fagan, S. Trudel, and C. P. Berlinguette, Water Oxidation Catalysis: Electrocatalytic Response to Metal Stoichiometry in Amorphous Metal Oxide Films Containing Iron, Cobalt, and Nickel, J. Am. Chem. Soc., 135(5), pp. 11580-11586, 2013.

[20] C. Xiang, S. K. Suram , J. A. Haber, D. W. Guevarra, E. Soedarmadji , J. Jin, and J. M. Gregoire, High-throughput bubble screening method for combinatorial discovery of electrocatalysts for water splitting, ACS Comb. Sci., 16(2), pp. 47-52, 2014.

[21] D. S. Dalavi, M. J. Suryanavanshi, D. S. Patil, M. S. S. Moholkar A.V. Kalagi S. S. Vanalkar, S. A. Kang, S. R. Kim, J. H. Patil, Nanoporous nickel oxide thin films and its improved electrochromic performance: Effect of thickness, Appl. Surf. Sci., 257(7), pp. 2647-2656, 2011. 